\title{
Numerical simulation of the propagation of a surface fire through a Mediterranean shrub
}

\author{
MORVAN D. ${ }^{(1)}$ and DUPUY J.L. ${ }^{(2)}$ \\ (1) Université de la Méditerranée UNIMECA Technopôle de Château Gombert \\ 60 rue Joliot Curie 13453 Marseille cedex 13 France \\ (2) INRA- PIF 20 Avenue Antonio Vivaldi 84000 Avignon France
}

\begin{abstract}
The propagation of a wildfire is simulated numerically from the resolution of the conservation equations (mass, momentum, energy...) of the system formed by the solid phase representing the vegetation and the surrounding gas mixture. The vegetation is represented by a collection of particles composed by a mixture of dry matter (wood), water, coal, plus a mineral residue (ashes). The physical parameters characterizing the various stages of the thermal decomposition of the vegetation (drying, pyrolysis, heterogeneous combustion) are evaluated from experimental data obtained by thermogravimetric analysis. The model describing the decomposition of particles is coupled with the calculation of the reactive turbulent flow resulting from the combustion of the pyrolysis products with the ambient air. The particles/gas coupling is ensured by production/destruction terms in the conservation equations of the chemical species. The drag force induced by the particles as well as the convective and radiative exchanges are also taken into account. The presence of soot particles in the flame and the composition of the gas mixture are taken into account to evaluate the absorption coefficient and the radiative intensity field. Calculations are carried out for various conditions of wind and a fire propagating in a layer of vegetation composed with a mixture of shrubs (Quercus coccifera) and grasses (Brachypodium ramosum) (characteristic of the Mediterranean zones on calcareous ground).
\end{abstract}

KEY WORDS : Wildfire modeling, Propagation, Multiphase Combustion

\section{INTRODUCTION}

Each year in summer Mediterranean regions are concerned by large scale wildfires which cause great damage to forest areas especially those situated near cities in the urban/forest interface. In the European Union (EU) countries, one counts each year nearly 50000 fire ignitions, representing a surface of 500000 ha, $-10 \%$ of fires alone account for $75 \%$ of destroyed surfaces [1]. The major part of these fire ignitions are detected at a sufficiently early stage to be controlled with modern methods of fire fighting (bombardiers, helicopters). Unfortunately by strong wind and for strong dryness conditions, this device cannot always be used (during the night for example), in this case a fire can become easily uncontrolled and take a catastrophic character. The understanding of the physical mechanisms which control the transition between an initially small surface fire and a large scale crown fire represent a real scientific challenge. This work must constitute the first step to develop operational tools to predict the development of wildfires in real conditions. The fire propagation models can be classified into three categories [2]: 
- the empirical models derived by establishing a correlation between the rate of spread (ROS) and conditions encountered by fire (nature and state of the fuel, weather conditions...),

- the semi-empirical models which are based on a simple energy balance (as the steady propagation is reached) connecting the energy absorbed by the layer of vegetation upstream of the fire (which is a fraction of the energy released by the reaction of combustion) and the energy necessary to ensure a sustained propagation of the fire,

- The physical models which are based on the more or less complete resolution of the equations of conservation (mass, energy, momentum...) which control the evolution of the variables in the gas phase and in the solid particles which constitute the vegetation,

The fire propagation models based on the empirical or semi-empirical approach, have the advantage of being sufficiently compact to be integrated in operational tools of forecast such as those used by various forest services (in USA, Canada, Australia), and in particular those developed from works of Rothermel [3] (BEHAVE, FARSITE...). This approach gives relatively correct results for a homogeneous vegetation on a flat ground (in fact for conditions close to those used to establish the correlation). Extrapolation to different conditions (heterogeneous vegetation, inclined ground, with wind effects) does not give satisfactory results. Other approaches were proposed thereafter based on a more physical formulation which takes into account the role of transfer phenomena (mass, momentum, energy, radiation) in the progression of fire.

Once the phase of ignition has passed, the fire propagation through a vegetation cover is assured if the energy received by solid fuel located ahead of the flame front is sufficient to initiate its degradation (vaporization, pyrolysis). Two mechanisms of heat transfer between the ignited zone and unburned fuel are identified, by radiation (embers and soots contained in the flame) and by convective exchange with hot gases.

The model that we developed can be described as multiphase physical approach $[4,5,6]$. It takes into account the mechanisms of thermal degradation (drying, pyrolysis, combustion of surface) of the solid particles composing the vegetation, the transfers of mass, momentum, and energy towards the gas phase, the turbulent transfers and the combustion which develop in gas phase as well as the radiative heat transfers coming from the embers and the flame. We applied this multiphase approach to the study of the propagation of a surface fire through a vegetation composed of a shrubby layer (Quercus coccifera) and of a herbaceous layer (Brachypodium ramosum) which is well represented in the Mediterranean basin (Figure 1). 


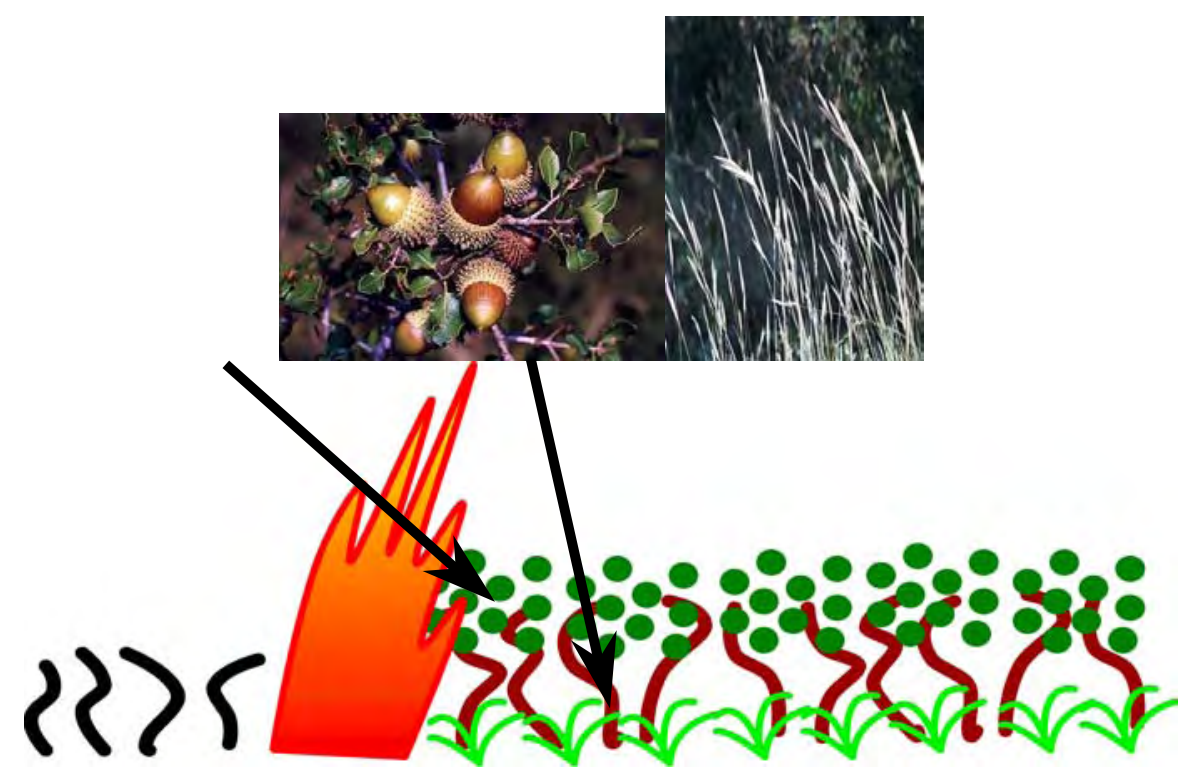

Figure 1: Propagation of a fire (schematic view) in a vegetation of the Mediterranean type composed of a shrubby layer (Quercus coccifera) and herbaceous (Brachypodium ramosum).

\section{MATHEMATICAL FORMULATION}

The model representing the degradation of the vegetation and its interaction with the surrounding gas mixture is one of the most significant parts of the formulation of this problem. The various elements composing the layer of vegetation are classified in families of particles according to their properties (size, density, volume fraction, moisture content...). Because most of the physical phenomena are located at the particles/gas interface, the significant properties which affect the rate of spread of a fire are the surface/volume ratio, the volume fraction and the moisture content of particles. The decomposition state of each family $(\mathrm{k})$ of particles is described from the mass fraction of water $\left(Y_{H 2 O}{ }^{s, k}\right)$, dry material (wood) $\left(Y_{i}^{s, k}\right)$, charcoal $\left(Y_{c h a r}{ }^{s, k}\right)$ and ash $\left(Y_{a s h}{ }^{s, k}\right)$. The initial state corresponds to a mixture of water and dry matter. Under the effect of the heat released by combustion (flame, embers) these particles lose their water and undergo a transformation (pyrolysis) which causes a release of gas products $\left(\mathrm{CH}_{4}, \mathrm{CO}, \mathrm{H}_{2}, \mathrm{CO}_{2}\right)$. These gases partly ignite in contact with the ambient air (homogeneous combustion). The remaining carbonaceous part of the particles (charcoal) also ignite (heterogeneous combustion). At the end of this decomposition process we obtain a mineral residue (the ashes) composed of silica oxide. Radiation and convection are the two mechanisms of energy transfer responsible for the progression of fire through the combustible layer:

- the radiation coming from the incandescent solid particles localized in the combustible layer (embers) and in the flame (soot),

- the convective exchanges with the hot gases produced in the burning zone.

The evolution of the state of each family of particles $\mathrm{k}$ is then described by the following series of differential equations [6]: 


$$
\begin{aligned}
& \frac{d \bar{\rho}_{s}{ }^{k} Y_{H 2 O}{ }^{s, k}}{d t}=\dot{M}_{H 2 O}{ }^{k} \\
& \frac{d \bar{\rho}_{s}{ }^{k} Y_{i}^{s, k}}{d t}=\dot{M}_{i}{ }^{k} \\
& \frac{d \bar{\rho}_{s}{ }^{k} Y_{c h a r}{ }^{s, k}}{d t}=\dot{M}_{c h a r}{ }^{k}=\dot{M}_{c h a r}{ }^{\operatorname{Pr},{ }^{k}}-\dot{M}_{c h a r}{ }^{O x y, k} \\
& \bar{\rho}_{s}{ }^{k} C_{p}{ }^{s} \frac{d T_{s, k}}{d t}=h_{c}{ }^{k} \alpha_{s}{ }^{k} \sigma_{s}{ }^{k}\left(T-T^{s, k}\right)+\frac{\alpha_{s}{ }^{k} \sigma_{s}{ }^{k}}{4}\left(J-J^{s, k}\right)+\sum \dot{M}_{\alpha}{ }^{k} \Delta h_{\alpha}{ }^{s, k}
\end{aligned}
$$

With the following notations :

$\bar{\rho}_{s}{ }^{k}=\alpha_{s}{ }^{k} \rho_{s}{ }^{k}$ (effective density), $\alpha_{s}{ }^{k}$ (volume fraction)

$\dot{M}_{\alpha}{ }^{k}$ (production/destruction rate of water (h2o), dry material (i), charcoal (char))

$C_{p}{ }^{k}$ (specific heat), $T_{s, k}$ (temperature), $\sigma_{s}{ }^{k}$ (Surface/Volume ratio)

$h_{c}{ }^{k}$ (solid/gas convective heat transfer coefficient)

$J, J^{s, k}$ (luminance and radiation emission from hot particles)

Among the assumptions selected to establish this model, we did not impose thermodynamic equilibrium between gas and the particles $\left(T_{s, k} \neq T\right)$. The rates of production / destruction $\left(\dot{M}_{\alpha}{ }^{k}\right)$ which characterize the kinetics of the thermal degradation of the particles are evaluated (kinetics laws or temperature threshold) from a thermogravimetric analysis (TGA) carried out on samples representative of the Mediterranean vegetation [11]. These analyses do not show a different behavior from a vegetation species to another one, as shown on Figure 2. On this curve (Figure 2), one can note that evaporation and pyrolysis process are complete for $\mathrm{T}_{\mathrm{s}, \mathrm{k}}=373 \mathrm{~K}$ and $540 \mathrm{~K}$ (solid phase temperature) respectively.

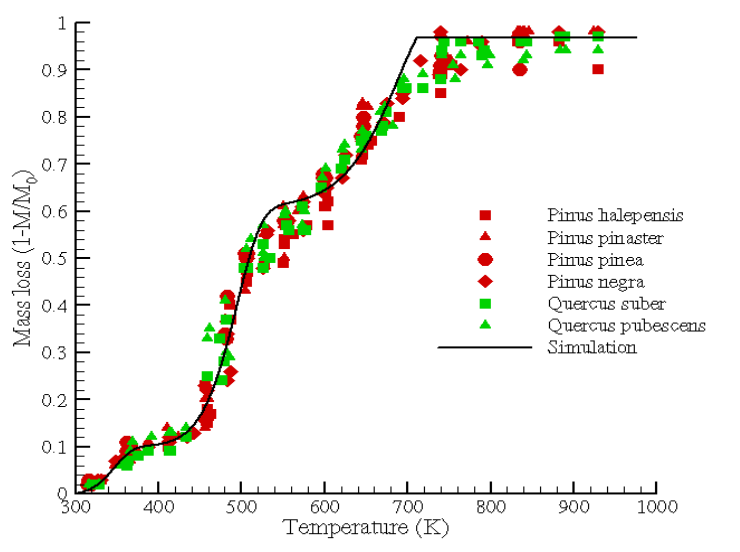

Figure 2 : Mass loss curve for various Mediterranean vegetation species [11]. 
The evolution of the gas phase is given from the conservation equations of the mass (total and for each chemical species), momentum, and energy, to which an equation of radiative transfer is added (RTE).

The turbulent transfers are evaluated from a eddyviscosity model using two transport equations (RNG $\mathrm{k}-\varepsilon)$ [7]. The calculation of the gas mixture is carried out using a turbulent mixing combustion model EDC [8] assuming that the products of pyrolysis are primarily composed of $\mathrm{CO}$ and $\mathrm{CO}_{2}[6]$.

The radiative transfer equation includes two source terms, the radiation released by the flame (the essence of this radiation comes from the soot particles located in the flame) and that emitted by the incandescent solid particles in the combustible layer (embers):

$$
\begin{aligned}
& \frac{d \alpha_{g} I}{d s}=\alpha_{g} \sigma_{g}\left(\frac{\sigma T^{4}}{\pi}-I\right)+\sum_{k} \frac{\alpha_{s}{ }^{k} \sigma_{s}{ }^{k}}{4}\left(\frac{\sigma T_{s, k}{ }^{4}}{\pi}-I\right) \\
& J=\int_{0}^{4 \pi} I d \Omega
\end{aligned}
$$

I indicates the radiative intensity, $\alpha_{\mathrm{g}}$ the volume fraction of the gas phase, $\sigma_{\mathrm{g}}$ the absorption coefficient of the soot+gas mixture, $\mathrm{T}$ the average temperature of the gas, $\mathrm{s}$ a direction of propagation. This equation is solved using a discrete ordinates method ( S8 scheme) (in 2D the field of luminance is then reconstituted from 40 directions) [9]. The other transport equations (mass, momentum, energy) are solved using a finite volume method ULTRA-SHARP associating a high order convective scheme (in space) (QUICK for example) with a limiting flux strategy [ 10 ], the time integration is performed using a second order Euler scheme. The pressure/velocity coupling is solved using a segregating iterative pressure correction solver.

\section{RESULTS AND DISCUSSION}

Calculations were carried out for a line fire assuming that the heat transfer between the fire front and the unburned solid fuel is mainly oriented in a plane perpendicular to the direction of the fire front and parallel to the direction of propagation. In this case the study can be limited to a $2 \mathrm{D}$ calculation, in a rectangle of $20 \mathrm{~m}$ length and $5 \mathrm{~m}$ height. The vegetation on the ground level (thickness $\mathrm{Y}_{1}=50 \mathrm{~cm}, 5 \leq x \leq 20 \mathrm{~m}$ ) is composed of shrubs (Quercus Coccifera) and of grasses (Brachypodium ramosum) which can be represented in the form of three families of particles distributed as following:

Quercus: (branches) $0 \leq z \leq 0.5 \mathrm{~m}$, (leaves) $0.25 \leq z \leq 0.5 \mathrm{~m}$, Brachypodium: $0 \leq z \leq 0.25 \mathrm{~m}$ During summer these various fuels particles are characterized by the following properties:

\begin{tabular}{|l|c|c|c|}
\hline & Quercus (branches) & Quercus (leaves) & Brachypodium \\
\hline Surface/Volume $\left(\mathrm{m}^{-1}\right)$ & 4000 & 4000 & 10000 \\
\hline Moisture content $(\%)$ & 70 & 70 & 5 \\
\hline Density $\left(\mathrm{kg} / \mathrm{m}^{3}\right)$ & 900 & 820 & 400 \\
\hline Volume fraction $(\%)$ & 0.1 & 0.15 & 0.1 \\
\hline
\end{tabular}


To ensure a constant level of accuracy during the calculation, the grid is recomputed using an adaptative mesh algorithm, to follow the progression of the fire front [ 4 ]. The computational domain is decomposed using $80 \times 45$ control volumes in the longitudinal (x) (parallel to the propagation) and the vertical (z) direction respectively, the mesh size in the more refined region is $\delta \mathrm{x}=10 \mathrm{~cm} \mathrm{X} \delta \mathrm{z}=3 \mathrm{~cm}$.

The results presented on Figure 3 show the temperature field (gas) and the velocity vector field (zoom) obtained for three wind speeds $\mathrm{U}_{\mathrm{H}}$ evaluated $2 \mathrm{~m}$ above the ground level $\left(\mathrm{U}_{\mathrm{H}}=1 \mathrm{~m} / \mathrm{s}, 5 \mathrm{~m} / \mathrm{s}\right.$ and $\left.10 \mathrm{~m} / \mathrm{s}\right)$ (the two dotted lines show the limit of separation between the various layers of the vegetation).
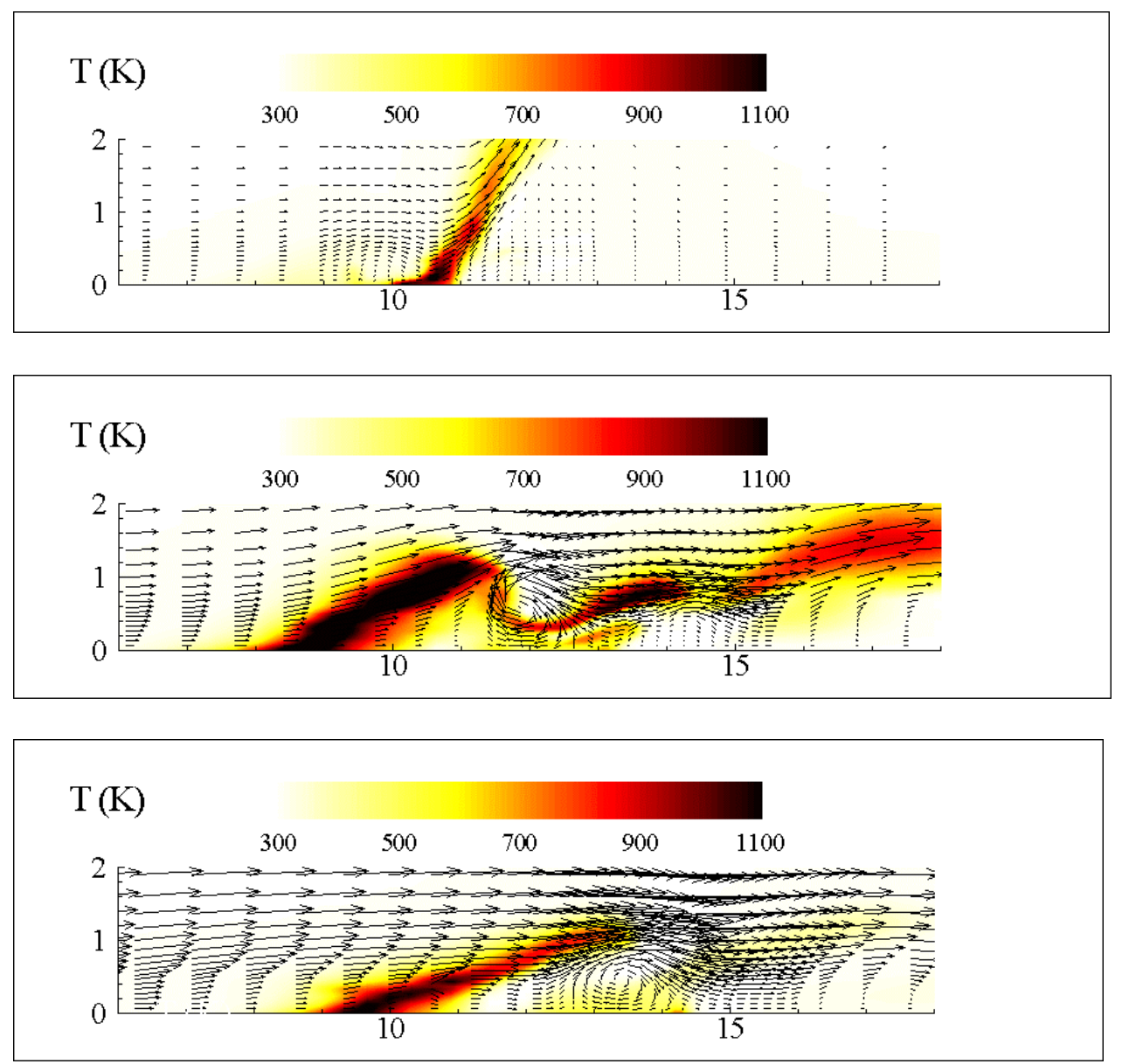

Figure 3 : Temperature field (gas phase) and velocity vectors (zoom) for three values of wind velocity $\left(\mathrm{U}_{\mathrm{H}}=1,5\right.$ and $\left.10 \mathrm{~m} / \mathrm{s}\right)$ (top to bottom).

For a weak wind conditions $\left(\mathrm{U}_{\mathrm{H}}=1 \mathrm{~m} / \mathrm{s}\right.$ ), the flame is almost vertical, the flow of oxygen which feeds the ignited zone comes from the zone located just upstream of the flame front. In this case the principal mechanism of propagation comes from the radiation emitted by the incandescent particles (soot + embers). For stronger wind conditions, the mechanisms of heat transfer are modified. Pushed by the flow downstream (wind) the hot gases cross the flame front and heat the fresh fuel located 
upstream. In this case the progression of fire is not only controlled by the radiative transfers, but also by the convective exchanges between the hot gases and the particles. Figures 4 and 5 show the energy received by the vegetation by radiation (Figure 4 ) and convective heat transfer with the gas (Figure 5), for various values of the wind speed.
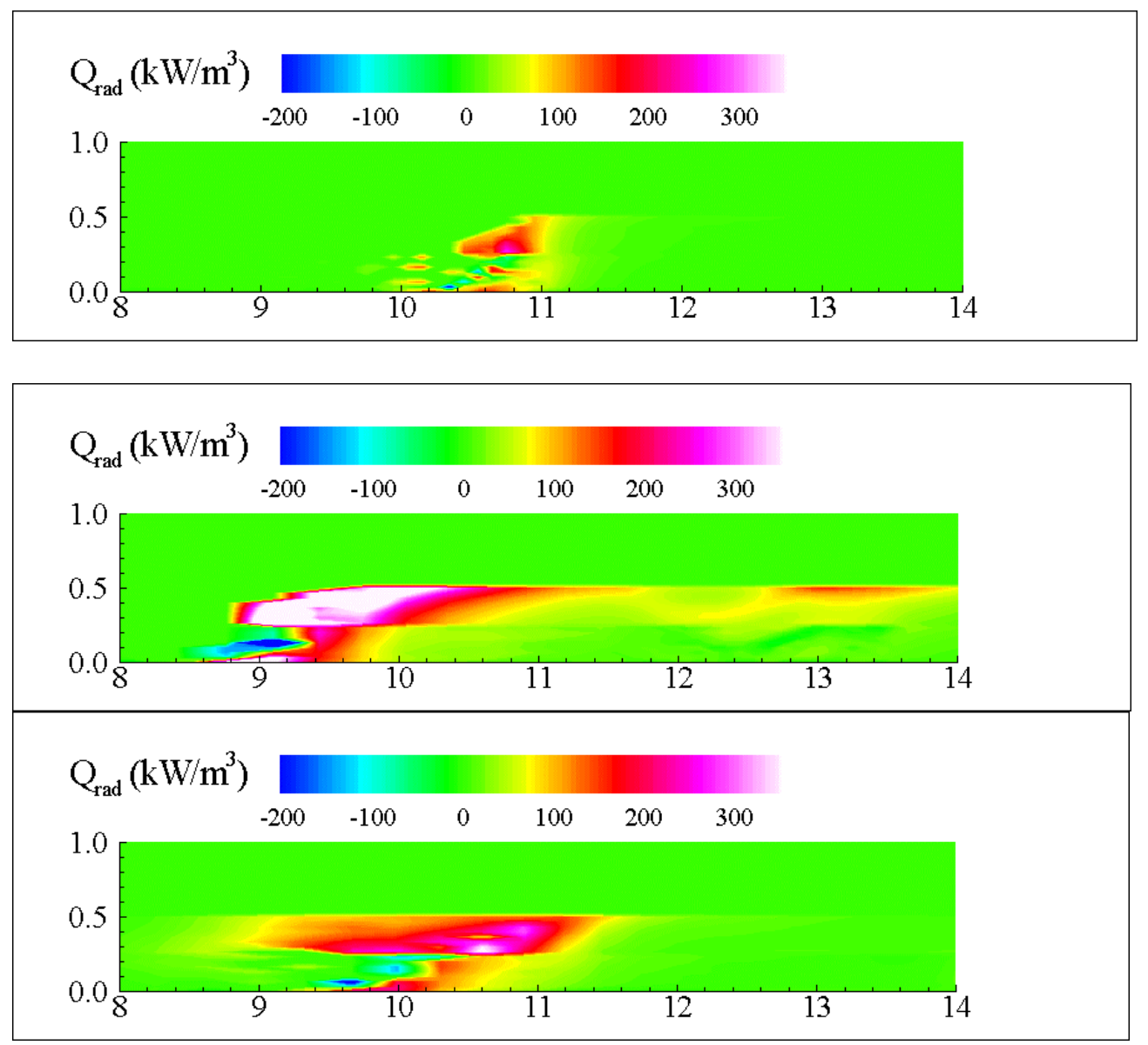

Figure 4 :Radiative energy received by the vegetation (zoom) for three values of wind velocity $\left(\mathrm{U}_{\mathrm{H}}=1,5\right.$ and $\left.10 \mathrm{~m} / \mathrm{s}\right)$ (top to bottom).

These results show that for weak wind conditions $\left.U_{H} \leq 2 \mathrm{~m} / \mathrm{s}, F_{r} \leq 1\right)$ the heat flow is dominated by the radiation heat transfer $\left(\mathrm{Q}_{\mathrm{rad}} \sim 60 \%\right)$. The reinforcement of the wind conditions causes an increase of the convection heat transfer, for medium wind conditions $\left(3 \leq U_{H} \leq 6 \mathrm{~m} / \mathrm{s}, 1 \leq F_{r} \leq 6\right)$ radiation and convection heat transfers are in equilibrium. For stronger wind speed $\left(U_{H} \geq 7 \mathrm{~m} / \mathrm{s}, F_{r} \geq 8\right)$, the flame temperature decreases and its radiative emission is strongly reduced, in this case the radiation does not represent no more than $30 \%$ of the energy received by the solid fuel.

The ratio between these two modes of heat transfer reaches a constant value around $70 \%$ as shown on Figure 6, which is in agreement with the experimental measurements [12]. 

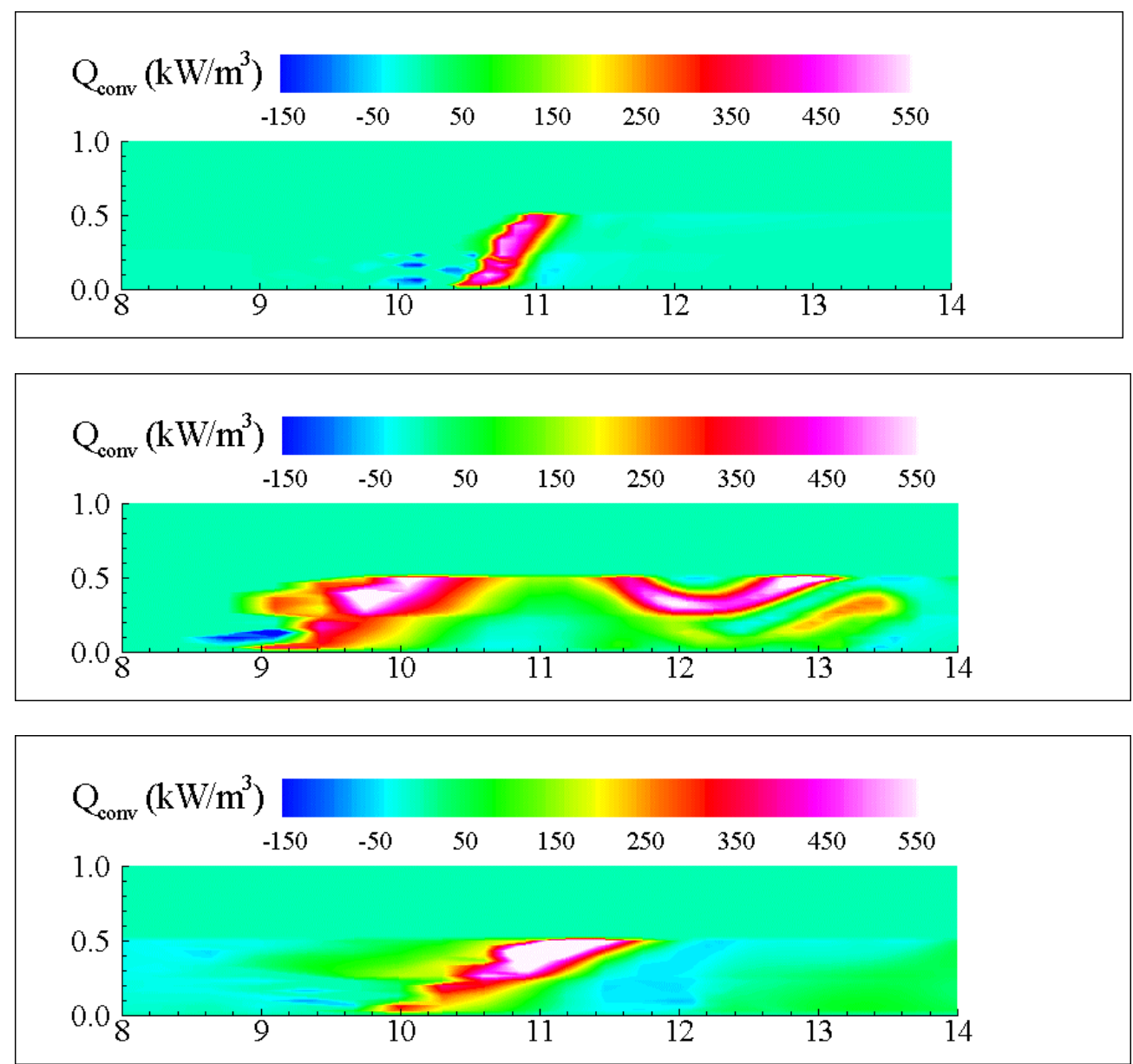

Figure 5 :Convective energy received by the vegetation (zoom) for three values of wind velocity $\left(\mathrm{U}_{\mathrm{H}}\right)$.

In wind-aided fire spread, the column of hot gases above the flaming zone forms an effective barrier against the wind field, which is partially deviated vertically [13] (see Figure 3) which explain that the radiative heat transfer remains the dominant mode of energy transfer between the fire front and the unburned fuel.

To compare the influence of the wind on the propagation velocity of fire (ROS), one can form a Froude number representing the ratio between the inertia force with the buoyancy force:

$$
F_{r}=\frac{U^{2}{ }_{H}}{g Y_{l}}
$$

On the results represented on Figure 7 it is clear that the convective effects start to be significant for a wind speed corresponding to a Froude number $F_{r}=1$, i.e. as the inertia forces become of the same order of magnitude as the buoyancy force. Below this value the effects of the wind are negligible compared to the buoyancy driven flow (thermal 
plume) (see also Figure 3 on the top). For moderate value of the Froude number $\left(F_{r} \leq 6\right)$ the ROS varies quasi linearly with the square root of the wind speed. Whereas in experiments a linear dependence of the propagation velocity with the wind speed has been observed, both for small scale fires in a wind tunnel [14] and for real outdoor fires in shrub fuels [15]. Nevertheless these experimental studies have been carried out for small range of wind velocity, for which it is difficult to make the distinction between a linear variation and a square root variation. However other studies (theoretical and experimental) have showed similar behavior for the propagation velocity according to the square root of the wind speed [16].

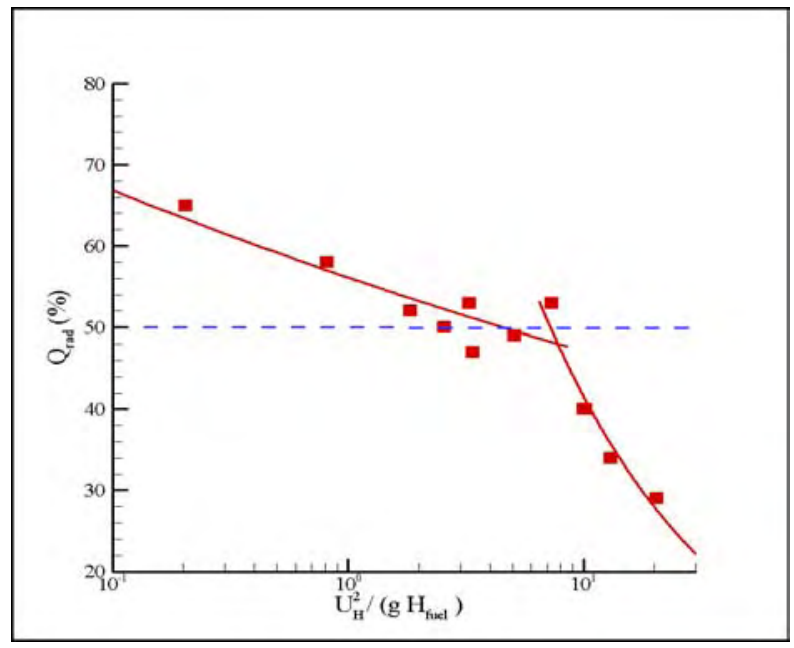

Figure 6 : Radiation heat transfer $(\%)$ received by the vegetation $\left(\mathrm{Q}_{\mathrm{rad}} / \mathrm{Q}_{\text {total }}\right)$ as a function of the Froude number.

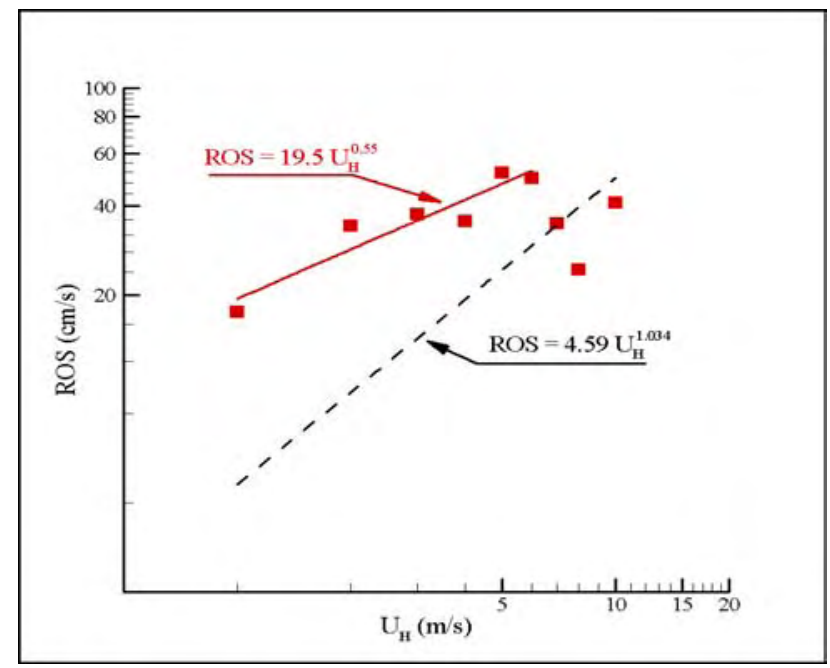

Figure 7 : Rate of spread (ROS) of the fire front as a function of the wind speed at $2 \mathrm{~m}$ (Numerical (squares) and experimental (dashed line) correlation [15]). 


\section{CONCLUSIONS}

The propagation of a wildfire through a Mediterranean shrub has been simulated numerically using a multiphase formulation. The numerical simulations have pointed out the relative influence of the radiadion and convection heat transfers upon the fire spread regime as a function of the wind velocity. For plume dominated fire $\left(\mathrm{F}_{\mathrm{r}}<1\right)$ the heat tranfer between the flame and the solid fuel is govern by radiation representing up to $60 \%$ of the energy received by the combustible layer. Then the heat flows received by radiation and convection are of the same order of magnitude. For wind-driven fire $\left(F_{r}>10\right)$, the convection heat flow becomes the main heat transfer mode.

\section{REFERENCES}

[1] "Forest and environment " Eurostat, Statistics in Focus Agriculture and Fisheries $\mathrm{n}^{\circ} 17(2000)$.

[2] Weber, R.O., " Modeling fire spread through fuel bed ", Energy Combust. Sci. 17:67-82 (1991).

[3] Rothermel, R.," A mathematical model for predicting fire spread in wildland fuels ", Technical report, USDA Forest Service Research paper INT-115 (1972).

[4] Morvan, D., Porterie, B., Larini, M., Loraud, J.C., “ Numerical modelling of reverse combustion in a fuel bed of pine needles ", Fire Safety Science--Proceedings of the Sixth International Symposium, International Association for Fire Safety Science, Interscience Communication, London, UK, 2000, pp. 695-706.

[5] Porterie, B., Morvan, D., Loraud, J.C., Larini, M., “ Firespread through fuel beds : modeling of wind-aided fires and induced hydrodynamics ", Physics of Fluids 12(7): 1762-1782 (2000).

[6] Grishin, A.M., Mathematical modeling of forest fires and new methods of fighting them , Publishing House of the Tomsk University, Tomsk, Russia, F. Albini (Ed.) (1997).

[7] Yakhot, V., Orszag, S.A., "Renormalization grop analysis of turbulence ", J. Scientific Computing 1(1): 3-51 (1986).

[8] Magnussen, B.F., Hjertager, H., “ On mathematical modeling of turbulent combustion with special emphasis on soot formation and combustion ", Proceedings $16^{\text {th }}$

Symposium (International) on Combustion, The Combustion Institute, 1976, pp. 719-729.

[9] Siegel, R., Howell, J.R., Thermal radiation heat transfer, Hemisphere Publishing Corporation, $3^{\text {rd }}$ Edition (1992).

[10] Leonard, B.P., Mokhtari, S., “ Beyond first-order upwinding : the ULTRA-SHARP alterative for non-oscillatory steady state simulation of convection ", Int. J. Nmerical Methods Engineering 30:729-766 (1990). 
[11] Grossiord, R., Moro, C., “ Décomposition thermique de particules de combustibles forestier méditerranéens “, Rapport Interne INRA-PIF9803 (1998).

[12] Pitts , W.M. ,"Wind effects on fires", Prog. Energy Combust. Sci., 17:83-134 (1991).

[13] Albini, F.A., "A model for fire spread in wildland fuels by radiation", Combust. Sci. And Tech.. 42: 229-258 (1985).

[14] Catchpole, W.R., Catchpole, E.A., Butler, B.W., Rothermel, R.C., Morris, G.A., Latham, D.J., "Rate of spread of free-burning fires in woody fuels in a wind tunnel", Combust. Sci. \& Technol. 131: 1-37 (1998).

[15] Martins Fernandes, P.A., "Fire spread prediction in shrub fuels in Portugal", Forest Ecology and Management 144:67-74 (2001).

[16] Carrier, G.F., Fendell, F.E., Wolff, M.F., "Wind-aided firespread accross arrays of discrete fuel elements", Combust. Science \& Technology 75:31-51 (1991). 
